\title{
Introduction to Perceptual Encounters: "Sensing" the Field of Human-Animal Studies
}

\author{
Valerie L. Stevens \\ Department of English and Modern Languages, Shepherd University, \\ Shepherdstown, WV, USA \\ vstevens@shepherd.edu
}

We first came together at the Human-Animal Studies Summer Institute Program in the summer of 2017. Hosted by the Animals and Society Institute and the University of Illinois Urbana-Champaign, this symposium was an opportunity to hear from and ask questions of people in the field of human-animal studies, to give and receive feedback on works in progress from colleagues in a range of fields, to see and listen to examples of animal-centered art, to visit a local goat farm, and to engage with the multitude of species found in Champaign, Illinois. Many encounters took place at this event.

Early career scholars mingled with people who helped to build the field of human-animal studies. Academics who frequently work within traditional fields of study collaborated across disciplinary boundaries. The fine arts met the humanities. The hard sciences met the social sciences. Artists, musicologists, literary critics, gender studies scholars, historians, sociologists, political scientists, veterinarians, equine therapists, lawyers, and many more were working together in the same space. Those who primarily identify as researchers joined academics whose main identity is that of teacher. Some considered themselves activists first. Vegans and vegetarians dined at the same tables as pescatarians and meat-eaters.

We all encountered nonhuman life: the companion dogs who came to visit with people who lived nearby; the goats and dog at the aforementioned farm; an injured owl and falcon from a local wildlife rescue; the snake brought in by a member of the group; the fireflies or lightning bugs that were a phenomenal new sight for some participants from other countries; the campus squirrels; the dead baby rabbit found on a sidewalk that a colleague decided to bury; and for some of us, the food on our plates. With all these encounters, slippages occurred between humans and nonhuman animals, between fields of study, 
between individuals. The purpose of this collection is to address some of these places where boundaries break down, where different entities and concepts meet each other, and where power and meaning are built through perceptual encounters.

Leaving the Human-Animal Studies Summer Institute Program, there was a desire to take these new connections - between individuals; between fields; between colleges, universities, and centers; and between species - with us. We did not just want to go back to our specific geographic locations, our jobs at particular institutions, our individual research projects, and forget the knowledge that could be gained and shared through new encounters. When the suggestion was made that we collaborate on some vehicle to share our wideranging research, several of us jumped at the opportunity to collaborate. What follows in this special issue of Society \& Animals, titled Perceptual Encounters: "Sensing" the Field of Human-Animal Studies, is the result of that drive to keep working together and building bridges.

Human-animal studies, by definition, is an interdisciplinary or transdisciplinary field of study that does not follow the frequently siloed nature of the academy. For instance, my individual research is informed by literary studies, animal studies, gender studies, and history, and other writers in this issue have similarly wide-ranging reference points in their work. Part of the impulse towards interdisciplinarity is the belief that crossing academic boundaries also encourages intersectionality. Of course, the scholars featured in this collection are pulled toward animal welfare activism, but their work is also politically engaged in other ways, particularly through interests in environmental studies more generally; race, class, nation, gender, and women's studies; affect theory and theories of care; and psychoanalytic theory.

Moreover, because the contributors to this collection are all emerging scholars, the politics of academic precarity and labor practices also inform their thinking. On the one hand, human-animal studies scholarship has the allure of still being a burgeoning field. Originary works were published in the 1980s, such as Turner's Reckoning with the Beast (1980), Thomas's Man and the Natural World (1983), and Ritvo's The Animal Estate (1987) in my field focusing on human-animal relationships in England, particularly in the nineteenth century. These historical accounts gave way to highly theoretical studies, including Derrida's The Animal That Therefore I Am (originally given as a talk in 1997, and ultimately published in English in 2008) and the posthumanism of Wolfe (2009) and (possibly, as will be discussed) Haraway (2008, 2016).

Amidst this work, Society \& Animals was started in 1993. Clearly there is an established history of human-animal studies at this point, but compared to 
the long past of many of our other academic disciplines, that narrative seems short. While there is the appeal of innovative newness within animal studies, this relative novelty also comes with the dangerousness of being less wellestablished, something that is not lost on the contributors to this issue, especially Seven Mattes, Aviva Vincent, and Cameron T. Whitley in "Emerging with Oddkin: Interdisciplinarity in the Animal Turn." Mattes, Vincent, and Whitley each reflect on skeptical would-be mentors questioning their research interests and career trajectories. The perception here was that human-animal studies was too niche, a fad, or less important or legitimate than human-centered work. The scholars in this issue work to shift that conception by showing both the intellectual and practical benefits of this field of study.

Importantly, the call to decenter the human does not mean forgetting the human, especially those in marginal positions. In When Species Meet (2008), Haraway eschews the title "posthumanist," knowing that human oppressions still remain pertinent in the lives of many:

I never wanted to be posthuman, or posthumanist, any more than I wanted to be postfeminist. For one thing, urgent work still remains to be done in reference to those who must inhabit the troubled categories of woman and human, properly pluralized, reformulated, and brought into constitutive intersection with other asymmetrical differences. (p. 17)

At the same time, Haraway argues for "worldliness and touch across difference" (p. 14). Obviously, this means different species, but also different experiences and even different fields of study. A recent pedagogical collection which is reviewed in this issue, titled Animals in Environmental Education (2019), has Lloro-Bidart (who was also a participant in the 2017 Human-Animal Studies Summer Institute Program) emphasize the significance of "incorporating an intersectional perspective not present in all interdisciplinary teaching and research" (p. 64). While we acknowledge the constraints of this issue that is broad but certainly not all-encompassing in scope, we see an exploration of intersections between different abuses - against humans and nonhuman animals - as a central aim of this project and other human-animal studies work. Environmental issues impact humans as well as nonhumans (and disproportionately people of color and those of lower socioeconomic positions), and gender and class-based exploitation is related to the corrupt use of nonhuman animals. At the same time that this collection asks us to look at - to perceive - this violence, it also emphasizes the potential for empowering encounters between agentive humans and animals, especially in art. 
The call to encounter difference also urges us to look beyond the academy. The intended audiences for Ruth K. Burke's The Process of Coming and Going in the World, an art installation at a farm, and Hayley Singer's "Lamb Nationalism" are not just scholars, but rather the general public who encounters animals and cultural narratives about our treatment of them in their day-to-day lives. Sara Granovetter's article considers the lived experiences of activists on the ground witnessing animal slaughter in an attempt not just to save individual animals, but rather to take these experiences of violence back to the broader population, to get more people to pay attention, and in doing so, to create change.

Many of the contributors to this collection reach a broad audience through our teaching of general education and specialized courses filled with many students who will go into non-academic careers. We see this in Seven Mattes, Aviva Vincent, and Cameron T. Whitley's article that thinks through best practices in academic mentorship, as well as their book review of Animals in Environmental Education: Interdisciplinary Approaches to Curriculum and Pedagogy. Moreover, featured authors have careers in therapy (Granovetter) and social work (Vincent) that involve directly aiding the public. We echo the importance of intersectional encounters, while also emphasizing the special relevance of these contacts for public-facing scholarly work. The writings featured in this collection are not just intellectual ponderings for an academic audience, but rather reflective of thought that has real-world implications for humans and nonhumans, particularly in the present moment that features mass animal slaughter, environmental degradation including climate change, and devaluing of scientific knowledge and facts.

So we encounter nonhuman animals and different scholarly fields engaged with the related topics of animal and human welfare in this issue. These contacts require acknowledging both the beauty and ugliness, the pleasure and the violence of human-animal encounters. By considering the complex relationships between species and disciplines, we are able to get a rich sense of the field of human-animal studies and of everyday human-animal relationships. This perception of ourselves as scholars and co-inhabitants of the world with animals is dependent on affective and sensory connections. Here it is helpful to think beyond human-animal studies scholarship to Sedgwick's (2003) discussion of the connection between touch, intimacy, and emotions - her attention to the dual meanings of "touching" as a physical encounter and as something that is emotionally moving.

In animal studies specific scholarship, these affective bonds can be largely positive, as with Smuts's (2008) notion of "embodied communication," a process in which "meaning is mutually constituted, literally embodied as two individuals' behaviors ('the parts') combine to create something new ('the whole')" 
(p. 137). Although some encounters are close and intensely intimate in a way that may be empowering, Chez's (2017) description of "emotional prosthesis" reminds us that intimacy can also be violent and exploitative. Even when we try to end or alleviate animal misuse, witnessing and perhaps even perpetrating violence against animals can be necessary. To get at these conceptual complexities in the following pages, we consider Violent Encounters, Embodied Performances, and Academic Applications. We use these themes to evaluate the present and look to the future of human-animal studies.

\section{Violent Encounters}

The first section of the special issue is on Violent Encounters. In "Lamb Nationalism," Australian poet Hayley Singer addresses the connection between animal slaughter and national identity. Singer calls into question the narratives that we tell ourselves about our collective character, tales which insist that killings are necessary and "required," that they are "not customary," that the dead animals are "consumed locally," and that this death is part of "tradition." Guides point back to a supposedly innocent past of slaughter that necessitates a similarly corrupt present: "Our guides say, / back then, no one suspected / the soundness of the scheme ... NO ONE SUSPECTED / THE SOUNDNESS / OF THE SCHEME" (p. 657). Singer forces the reader to think critically about the story being told by her repetitions in language and the shouting capitalizations. By challenging this story of nationhood and anthropocentric bloodshed, Singer exposes the way repetitions become misunderstood as truths and traditions mask violence, hiding that cruelty against animals in plain sight. Implicit in the poem is that the reader should find the scheme - the national narrative and the systemic violence against nonhuman animals that the tale obscures - suspect.

The subsequent article likewise takes animal slaughter as its topic. Sara Granovetter's "Activist as Symptom: Healing Trauma Within a Ruptured Collective" explores the impact of witnessing violence against animals on factory farms on the activists who choose to engage with this mass death. While there is a more extensive body of scholarship that looks at the animals on farms who are killed and exploited by this system and at the workers in the factory farms (Singer, 1975; Adams, 199o; Coetzee, 1999; Animal Studies Group, 2006), Granovetter is one of the few scholars to focus on the traumatic experiences of animal rights activists as they encounter and resist the epic abuses against animals used for food. According to Granovetter, "[i]n their willingness to experience nonhuman suffering as their own, interviewed activists become 
the carrier group for collective trans-species trauma" (p. 66o), and ultimately "activists express symptoms for animals who are precluded from speaking for themselves" (p. 674).

Importantly, Granovetter does not just outline the problem of factory farming (though, of course, she does that too), but rather she calls for "collective witnessing" as a solution. The activists currently watching and resisting the violence against animals are necessary, often sacrificing their wellbeing to expose abuses against nonhuman others, but it is crucial that more people from the larger population take heed of what is happening to nonhuman animals on an unfathomable scale for change to actually take place. In this special issue, both Singer and Granovetter present calls to action, particularly asking readers to revise their ways of thinking by a willingness to encounter nonhuman animal suffering.

While Singer and Granovetter both give voice to animals used for food by critiquing the violence against them, Valerie L. Stevens considers the imperfect possibility of merciful violence against animals in "Embodied Violence Towards Nonhuman Animals in Anne Brontë's Agnes Grey." If Singer asks us to question narratives of national identity in relation to animal slaughter, Stevens complicates the way we mythologize human-animal sympathy from past eras, particularly challenging perceptions of Victorian kindness towards animals as sweetly affectionate. In order to question this cultural memory of saccharine sympathy, Stevens analyzes Anne Brontë's Agnes Grey (1847), focusing on the dead animal bodies that keep showing up in the pages of the novel as meat on tables, hunted prey, and victims of cruel children's violent whims.

Particularly striking in Brontë's novel is a scene in which the title character, a governess, kills a batch of nestlings to keep them from being tortured by her young male pupil. While proper women were perceived as merciful, this act defies gender expectations in that it goes against upper-class male authority and is physically violent. By focusing on embodied violence, it becomes evident that the one would-be killer callously destroying the animal and the other trying to preserve the animal from further suffering by bringing death both have to physically encounter and engage with the animal in pain. Ultimately, Stevens highlights that "the violence of mercy and cruelty [can] look much the same, and [when this happens] the idea of sympathy as an easy to observe mode of feeling falls apart" (p. 682). While merciful violence is certainly problematic, the author does ask if it is necessary regardless within the world of the novel. As the activists of Granovetter's article have to bring trauma upon themselves to ultimately spare animals from pain, Agnes, too, chooses to encounter violence to ease suffering. 


\section{Embodied Performances}

Even though training animals to perform can be a violent or exploitative act, the pieces in the Embodied Performances section of this special issue show that human-animal performance can be a creative venue in which animal agency remains intact. The first piece in this section, "The Process of Coming and Going in this World: A Conversation about Interspecies Collaboration, Domestication, and Sound," is an interview between art historian Jessica Landau and artist Ruth K. Burke. In this conversation, Landau and Burke discuss the latter's art installation, The Process of Coming and Going in this World, in which the audience visits an open shed located in a pasture with animals.

So often as humans engaging with art we depend on the anthropocentric sense of sight as we read texts and images, but Burke's work emphasizes other senses, those which may be more dominant for other animals: the smell of the animals, the sound of feet walking on hay, the touch of a human hand encountering animal hide, the taste of the meal the audience shares at the farmhouse as part of the installation, and so much more. High art is replaced with the mundane and the bodily, and distancing visual representation is replaced with affective encounters in which art subject and audience, the human and nonhuman animal, and the competing senses are all blurred. Inspired by Temple Grandin's work on human-livestock encounters, Burke "co-labors" and collaborates with nonhuman animals, and consent is a central part of that shared work: "In my work, collaboration is contingent upon the unknown and potential refusal. This shared agency has aesthetic and conceptual value" (p. 708). Both the audience and the artist encounter animals through Burke's work, and the result is a keen awareness of the animal's power of choice, the ability of sensory communication common between humans and nonhumans, and a shared experience of worldliness.

Likewise, Katherine Altizer's “Is It Gonna Be Fun?': Dogs as Musical Performers and Audiences" looks at art in which human and nonhuman animals work together. With Laurie Anderson's documentary Heart of a Dog (2015) as her central text, Altizer considers the collaboration between the pianoplaying canine Lolabelle and her trainer Elisabeth Weiss. Altizer maps the long history in which dogs at the piano are considered mere comedy, musically derivative, a funhouse mirror version of anthropocentric musical art, and a way of emphasizing difference between human and nonhuman or canine "asifness" (Desmond, 1999, p. 240). Rather than dealing with the question "is this high quality music?," Altizer instead contemplates whether being at the piano is fun for the dog and whether it benefits their mental and physical wellbeing. 
Through analyzing Anderson's documentary and personal conversations with Weiss, Altizer concludes that, yes, Lolabelle's time at the piano was both enjoyable and advantageous for the dog, as well as her human trainer: "The connections among Weiss, Lolabelle, and pianistic activity appear to be mutually rewarding.... They offer an opportunity to re-route the frame for the activity from dismissal and as-ifness toward education and health" (p. 729). By reframing the discussion around canine wellness and fun, Altizer foregrounds the dog's agency. If she did not enjoy her time at the piano, she would not have played. Burke's animal collaborators described earlier and Lolabelle from Altizer's article all had the power of refusal at their disposal, making it all the more striking that they chose to participate in collaborative performance encounters with humans.

\section{Academic Applications}

The final section of this special issue (Academic Applications) explores how human-animal encounters can be applied within the academy, particularly through teaching and research. The first piece in this section is Seven Mattes, Aviva Vincent, and Cameron T. Whitley's "Emerging with Oddkin: Interdisciplinarity in the Animal Turn," a reflective exploration of the resistance that human-animal studies scholars often find within their home disciplines, especially as early career academics. Using the perspectives of an anthropologist, sociologist, and social worker, the article describes the intellectual community that is formed among animal studies scholars, who face similar challenges, share many of the same intellectual and personal interests, and are united in the commitment to moving scholarship beyond a focus on the human and siloed disciplines.

Rather than simply caving to professional pressures to do traditional, discipline-specific research, the authors encourage emerging scholars to "stay with the trouble" (borrowing from Donna Haraway's recent monograph of that title), defying the voices of scholars who have reservations about humananimal studies, finding support outside of typical departmental networks, and doing innovative interdisciplinary work with intersectional, real-world implications. In a sense, the article itself - with three authors from three different fields of study - as well as this special issue, with its collection of writers from the humanities and the social sciences, models the call for interdisciplinarity that this article raises.

The issue closes with a book review, also by Mattes, Vincent, and Whitley. In their evaluation of Animals in Environmental Education: Interdisciplinary 
Approaches to Curriculum and Pedagogy (edited by Teresa Lloro-Bidart and Valerie S. Banschbach), the authors commend the edited collection's emphasis on "intersectionality through interdisciplinarity" (p. 764). While the rest of Perceptual Encounters: "Sensing" the Field of Human-Animal Studies focuses on research, art, and activism, the thoughts on Animals in Environmental Education highlight the applicability of all of this work to the classroom and in public-facing education.

Ultimately, all of the work in this special issue in the humanities and social sciences - spanning from single-authored texts to collaborative scholarship and traditional academic articles to more exploratory reflective pieces, interviews, and poetry - seeks to articulate some of what we can perceive when encountering difference. Section 1 on Violent Encounters explores the necessity of witnessing, acknowledging, and maybe even perpetrating violence against animals in our anthropocentric world. Embodied Performances describes humans physically engaging with autonomous animals in art and music. The collaborative work referenced in this section is mutually beneficial for humans and nonhumans, sensorily rich, and breaks down the expectations for lofty art. Finally, the third section, Academic Applications, outlines the challenges and rewards of interdisciplinary human-animal studies work in practice, particularly in academic research, teaching, and social work. This collection reveals that, when we reach across difference, the categories we perceive as so important - species, academic disciplines, gender, art - begin to melt away.

\section{References}

Adams, C. (2010). The sexual politics of meat: A feminist vegetarian critical theory. New York, NY: Bloomsbury Academic. (Original work published 1990)

Animal Studies Group. (2006). Killing animals. Urbana, IL: University of Illinois Press. Chez, K. (2017). Victorian dogs, Victorian men: Affect and animals in nineteenth-century literature and culture. Columbus, $\mathrm{OH}$ : Ohio State University Press.

Coetzee, J. M. (1999). The lives of animals. Princeton, NJ: Princeton University Press.

Derrida, J. (2008). The animal that therefore I am. New York, NY: Fordham University Press.

Desmond, J. (2016). Displaying death and animating life: Human-animal relations in art, science, and everyday life. Chicago, IL: The University of Chicago Press. 
Grandin, T. (2017). Temple Grandin's guide to working with farm animals: Safe, humane livestock handling practices for the small farm. North Adams, MA: Storey Publishing.

Haraway, D. (2008). When species meet. Minneapolis, MN: University of Minnesota Press.

Haraway, D. (2016). Staying with the trouble: Making kin in the Chthulucene. Durham, NC: Duke University Press.

Lloro-Bidart, T., \& Banschbach, V. S. (Eds.). (2019). Animals in environmental education: Interdisciplinary approaches to curriculum and pedagogy. Cham, Switzerland: Palgrave Studies in Education and the Environment.

Ritvo, H. (1987). The animal estate: The English and other creatures in the Victorian era. Cambridge, MA: Harvard University Press.

Sedgwick, E.K. (2003). Touching feeling: Affect, pedagogy, performativity. Durham, NC: Duke University Press.

Singer, P. (2009). Animal liberation. New York, NY: Harper Perennial. (Original work published 1975)

Smuts, B. (2008). Embodied communication in non-human animals. In A. Fogel, B. King, \& S. Shanker (Eds.), Human development in the twenty-first century: Visionary ideas from systems scientists (pp. 136-146). Cambridge, United Kingdom: Cambridge University Press.

Thomas, K. (1983). Man and the natural world. Oxford, United Kingdom: Oxford University Press.

Turner, J. (1980). Reckoning with the beast. Baltimore, MD: Johns Hopkins University Press.

Wolfe, C. (2009). What is posthumanism? Minneapolis, MN: University of Minnesota Press. 